\title{
NATUREZA COMO FATO CULTURAL - O CONDEPHAAT E AS POLÍTICAS PÚBLICAS DE MEIO AMBIENTE
}

\section{Sandro Francisco Detoni ${ }^{1}$}

Resumo: Os elementos que compõem as estruturas físicas e biológicas da Terra são dotados de importância cultural em razão de suas dimensões simbólicas formais ou epistemológicas. Este artigo analisou os argumentos que embasam a inclusão da defesa e proteção da natureza no contexto das políticas culturais, o que pressupõe o reconhecimento de seus componentes como fatos culturais. Apresentam-se as premissas que definem e constituíram o conceito de patrimônio cultural, cujo sustentáculo fundamental está na própria amplitude simbólica dos bens culturais, engendrada nas relações sociais entre os membros de uma comunidade (ou sociedade) e dos grupos sociais com o suporte físico-natural. Tal característica corrobora a inclusão dos distintos componentes do quadro natural como um dos focos das políticas pública da área cultural, mais especificamente, o reconhecimento por meio do tombamento natural. Analisaram-se também os dados e o histórico sobre os tombamentos efetuados no Conselho de Defesa do Patrimônio Histórico, Arqueológico, Artístico e Turístico de São Paulo e as contribuições metodológicas da ciência geográfica, as quais possibilitaram a definição de critérios para a identificação dos atributos naturais dotados de significância cultural.

Palavras chave: Patrimônio cultural, áreas protegidas, tombamento natural, geografia

\section{NATURE AS CULTURAL FACT: THE CONDEPHAAT AND IT ENVIRONMENT PUBLIC POLICIES}

\begin{abstract}
The elements that make up the physic and biologic frameworks in Earth have cultural importance due to its formal symbolic dimension and epistemological characteristics. The purpose of this study was to analyze the arguments that offer support to include the nature as one category for cultural protection, which involve its recognition as cultural heritage. It was presented the premises that defined and constituting the concept of cultural heritage, whose base is the symbolic dimension of the cultural artifacts create in the relationship between the members of community (or society) and social group with the environmental. This characteristic allows including the nature frameworks, and its different components, as part of the cultural public policies, specifically, through recognition as nature heritage. Moreover, it was analyzed historic and data from protection by São Paulo Cultural Heritage Council. This institution have natural area protected based in methodological contributions that came from geographic science and result on parameters for identification of natural attributes with cultural significance.
\end{abstract}

\footnotetext{
${ }^{1}$ Professor de Ensino Superior III-D da Faculdade de Tecnologia de Barueri (FATEC-Barueri). E-mail: sandrogeousp@yahoo.com.br
} 
Keywords: Cultural heritage, protected areas, natural listed, geography

\section{INTRODUÇÃO}

Ao considerar alguns dos pressupostos antropológicos, a espécie humana se diferencia dos demais seres vivos em razão da sua dimensão cultural. A oposição entre natureza e cultura definem caminhos diferenciados na compreensão do funcionamento dessas categorias de análises. Ao pensar a defesa e a proteção dessas temáticas, cada qual é assistida por instrumentos jurídicos definidos em lógicas compartimentadas - a proteção da natureza fundamentada dentro de uma perspectiva tecnicista e universalizada; e a cultura baseada na compreensão dos seus condicionantes simbólicos de valores e significados. Logo, pensar a proteção de um ecossistema natural num órgão ligado às políticas culturais, num primeiro momento, pode parecer um contrassenso. Posto isso, este artigo tem o objetivo de conduzir a linha teórica que respaldou o reconhecimento da natureza, ou do quadro natural, compostos de objetos dotados de significados simbólicos passíveis de reconhecimento institucional na esfera da cultura. Apresentam-se os argumentos que sustentam a natureza no contexto da produção e reprodução das relações simbólicas dos grupos sociais e que envolve um sistema de apropriação coletiva. Com base no delineamento teórico, propôs-se um quadro esquemático que sistematiza as dimensões dos patrimônios culturais. Num segundo momento, analisaram-se os dados sobre os tombamentos realizados no âmbito do Conselho de Defesa do Patrimônio Histórico, Arqueológico, Artístico e Turístico do Estado de São Paulo (Condephaat) com o intuito de averiguar a amplitude dos tombamentos de áreas naturais pelo órgão e como se deu o processo de reconhecimento da natureza como um fato cultural dinamizado no interior dessa instituição.

\section{CULTURA E SEU CARÁTER SIMBÓLICO}

Etimologicamente, o termo patrimônio predispõe um sentido material e pode ser definido como o conjunto de objetos que pertencem à esfera individual ou familiar dos seres humanos, algo que se converte em herança econômica ou de propriedade.

A palavra patrimônio adquiriu uma nova vertente conceitual a partir da inclusão do dimensionamento cultural. Imbuiu-se ao vocábulo o caráter transmissivo de uma materialidade coletiva de grupos sociais. Assim, é possível afirmar que a expressão patrimônio cultural pertence à esfera da difusão das representações simbólicas coletivas. Por isso, ao incluir o adjetivo cultural ao patrimônio, o conteúdo denotativo sugere que os objetos possuam os seus valores pautados num conjunto de significados concebidos no âmbito dos grupos sociais. No contexto linguístico, a expressão patrimônio cultural se apresenta como um adjetivo relacional caracterizado pelo não posicionamento pré-nominal do qualificador, pela inexistência de antônimo e pela impossibilidade da sua flexão em graus. Tais balizadores gramaticais determinam a sua amplitude prática: não há objetos do patrimônio cultural de maior ou menor grau de importância, ou valoração, e não existe ou se impõe o seu contrário. Com isso, qualquer forma de expressão cultural é cabível de reconhecimento institucional, desde que se identifique o seu significado de expressão cultural.

Destaca-se que o patrimônio cultural possui níveis de abrangência espacial 
de reconhecimento: suas representações envolvem o reconhecimento internacional, nacional, regional ou local.

Dentro da linha analítica sobre os conteúdos expressos pelo termo patrimônio, fala-se também em patrimônio da humanidade, os quais indicam que o bem possui interesse para as nações, ou Estados, que se tornam signatários dos regimentos regulatórios descritos por cartas, convenções e tratados, como o do continente antártico ${ }^{2}$, caracterizado pela ausência de uma jurisdição estatal específica.

Para este artigo, interessa considerar que um patrimônio cultural carrega um conteúdo simbólico que valoriza relações expressas em objetos ou em manifestações ritualísticas estruturadas ou não por bases materiais, ou seja, podem ser materiais ou imateriais.

Há o interesse coletivo em se reconhecer os patrimônios culturais, em função, muitas vezes, de uma iminente supressão. O reconhecimento cultural pautase na atribuição de uma importância simbólica, seja para uma coletividade ou por meio de inventários pautados por argumentos técnico-científicos. Em ambos os aspectos, a natureza concebe conteúdos valorativos de reconhecimento e podem preconizar uma intervenção estatal instrumentalizado por um conjunto de políticas públicas de proteção ${ }^{3}$.

Nesse ponto, torna-se oportuno traçar algumas linhas gerais sobre o conceito de cultura e a sua oposição à natureza. Os diferentes aspectos que envolvem a noção de cultura distinguem a espécie humana das demais formas de vida existentes no planeta. A cultura é inerente aos seres humanos e pode ser interpretada como um conjunto de valores que servem de mediação simbólica entre os membros de uma comunidade (ou sociedade) e dos diferentes grupos sociais com a natureza. Com isso, a espécie humana, ao agir de forma individual ou coletiva, perante as leis ordenadoras da natureza, não está no mesmo patamar dos demais seres vivos.

A oposição entre cultura e natureza, engendrada numa das vertentes da antropologia, pode sugerir o afastamento das estruturas da natureza das práticas institucionais de proteção do patrimônio cultural. Todavia, os bens culturais, que são de diferentes tipologias, permitem incluir o quadro natural na qualidade de suporte físico e dotado de caráter simbólico para os grupos sociais.

A respeito do conteúdo simbólico dos bens culturais, Magnani (1986) descreveu a importância dos patrimônios como instrumentos de inteligibilidade dos códigos culturais:

A noção de patrimônio, desta forma, aponta para o aspecto da exterioridade da cultura; objetos, técnicas, espaços, edificações, crenças, rituais, instrumentos, costumes, etc., constituem os suportes físicos, as formas particulares e tangíveis de expressão dos padrões culturais. Como corolário desta análise, do ponto de vista da ação preservacionista, pode-se afirmar que esta incide não sobre a cultura em sim -; cujos processos constitutivos e de transformação estão sujeitos a determinações mais gerais, ditadas pela dinâmica social e política -, mas sobre seus suportes, manifestações e condições concretas de existência; e também não sobre todos, o que introduz

\footnotetext{
${ }^{2}$ Tratado da Antártica de 1959 que dispôs, entre outros aspectos, da cooperação internacional de utilização pacífica do continente antártico e seu interesse para pesquisas científicas.

3 Conforme se mencionou, por vezes, o objeto ou a área de interesse cultural integram um domínio público de reconhecimento internacional, o que não envolve a descaracterização da tutela estatal nacional.
} 
uma segunda qualificação a ser analisada no conceito de patrimônio cultural, que é seu caráter seletivo. (MAGNANI, 1986, p. 2).

O autor delineou a amplitude de possibilidades dos patrimônios culturais, o que permitiria a inclusão do quadro natural como objeto de proteção das políticas públicas das áreas culturais, afinal, a natureza se constitui como um suporte físico das representações culturais dos grupos sociais. Ressaltou-se também a seletividade como um dos determinantes no reconhecimento institucional de um objeto cultural. Nesse sentido, para Durham (1984), de certo modo, as classes dominantes dirigem a produção material e a cultural coletiva da qual se apropriam.

Pensando a questão desse ângulo, fica um pouco mais claro o que deve ser uma política oficial em relação ao patrimônio cultural numa sociedade que se quer democrática. Implica a ideia de um patrimônio cultural que, sendo na verdade produzido coletivamente, seja cada vez mais apropriado coletivamente, quer dizer, é necessário criar condições para que as pessoas, das mais diferentes classes, tenham condições de se apropriar daquele patrimônio que é mais carregado simbolicamente, que é mais rico e que, normalmente, é monopolizado pelas classes dominantes. (DURHAM, 1984, p. 33).

A questão do patrimônio cultural, além de envolver o monopólio de classe para o seu reconhecimento, enfrenta a concentração tipológica em determinadas categorias. Em outra vertente, verifica-se que a natureza, no jogo das relações sociais contemporâneas, perde o seu significado simbólico no campo da espontaneidade em razão da instauração do discurso do valor de troca, em detrimento ao valor de uso. A importância cultural da natureza ou mesmo dos outros objetos culturais passa a ser relegada e apropriada na lógica do consumo, ou seja, não ocorre mais de forma coletiva e sim para satisfazer os propósitos de um determinado grupo, uma a apropriação privada e mercadológica, o que a torna destituída de significado cultural. Tal característica se apresentaria como um impeditivo para a sua inclusão como objeto cultural.

Por outro lado, dentro de uma lógica corporativista, é possível verificar na seleção das categorias de bens culturais uma tendência à valorização das estéticas artísticas e construtivas, ou seja, o histórico, o arquitetônico e o artístico tendem a predominar na aplicação das políticas de proteção ao patrimônio cultural. Tal afirmação é consubstanciada pela análise quantitativa dos objetos de proteção cultural no conjunto das categorias de patrimônio cultural, conforme descreveu Detoni (2016).

A superação da política de concentração tipológica dos bens culturais perpassa pela inclusão e percepção da natureza como um objeto de apropriação simbólica aparte dos princípios ideológicos que ordenam o funcionamento contemporâneo da sociedade urbano-industrial. Uma política pública pautada no valor de uso da natureza. Um uso que pode envolver a sua simples contemplação simbólica.

\section{NATUREZA, PATRIMÔNIO CULTURAL E A SUA APROPRIAÇÃO ECONÔMICA}

Os princípios culturais irão determinar as relações entre as sociedades e a 
natureza, inclusive a forma de interpretá-la. Rússio (1984), ao destacar os aspectos culturais dos museus, destaca que a cultura é resultado do trabalho do Homem, seja na reflexão intelectual ou no seu resultado em uma construção concreta. Por meio dessa indagação, é possível afirmar que a construção concreta do trabalho humano necessita da natureza, não somente no fornecimento de insumos materiais, mas também como objeto de reflexão intelectual. Com isso, a paisagem e o ambiente físico natural são fatos culturais que possuem significados, valores e funções atribuídos pelo Homem e se tornam, em determinado momento histórico os objetos patrimoniais coletivos.

Nesse contexto, a atribuição de significados e de valores é estritamente cultural. A prática de preservação, seja da natureza (stricto sensu) ou da cultura, é uma ação intelectual que decorre de uma significação de caráter cultural.

A percepção social da proteção dos objetos culturais pressupõe a atribuição de significado ou de um valor, sobretudo, no seu iminente risco à degradação ou da sua suplantação paisagística. A necessidade das práticas de preservação ou conservação sobre a natureza pode envolver um conteúdo científico do qual não se expressa, aparentemente, um valor coletivo. Por isso, a ação política, além de se configurar num ato de administrar conflitos, envolve o esclarecimento sobre o valor dos objetos. No contexto de proteção do patrimônio cultural, essa ação inclui as atividades de identificação, de proteção e de valorização das formas de expressão e de materialidades culturais.

A ação prática do estabelecimento do patrimônio cultural implica na formação de estruturas operacionais de reconhecimento, a partir de determinados referenciais valorativos. Para Meneses (1996), o valor cultural é produzido no jogo das relações sociais, portanto, ele não está nas coisas ou objetos, mas no resultado de uma construção social e histórica. Nesse sentido, Meneses (1992; 1996) sugeriu 4 categorias de valor que deveriam ser capazes de operar a definição do significado de um bem: os valores cognitivos, os formais, os afetivos e os pragmáticos.

$\mathrm{Na}$ proposta elaborada por Meneses (1992; 1996), os valores cognitivos se referem às dimensões do conhecimento, o que envolve os saberes e as condições técnicas, sociais, econômicas, políticas, ideológicas e simbólicas de produção, de práticas e de representações. Constituem-se como os suportes aos conhecimentos diante de uma perspectiva histórica.

As condições físicas ou estáticas dizem respeito à valoração formal e relacionam-se à valorização de determinados padrões estéticos - possibilidade de certos atributos formais potenciarem a percepção num dado contexto sociocultural.

Os valores afetivos e os pragmáticos caracterizam-se pelas relações subjetivas coletivas com espaços, estruturas e objetos. Todavia, os valores pragmáticos, observados em muitos pedidos para o reconhecimento da natureza como patrimônio cultural, pertence ao denominado valor de uso e se constituem no principal foco dos conflitos de tombamento quando se impõe as dinâmicas impostas pelo valor de troca. Tais valores resultam da relação de afetividade e determinam a significância dos objetos por meio dos seus usos.

As sistematizações sobre as esferas patrimoniais, geralmente, o dividem em cultural e natural, material e imaterial. Sugere-se que o patrimônio natural é uma dimensão do patrimônio cultural, logo, a institucionalização da natureza como um patrimônio também pressupõe a sua componente simbólica no universo de sua percepção social.

Com base nas posturas teóricas analisadas e nas experiências práticas no âmbito do patrimônio cultural, propõe-se o Quadro 1. Considera-se que todo 
patrimônio diante do seu contexto simbólico e coletivo é cultural. Com isso, conforme a sua categoria, é possível definir alguns elementos estruturantes.

Quadro 1. Proposta de sistematização do patrimônio cultural

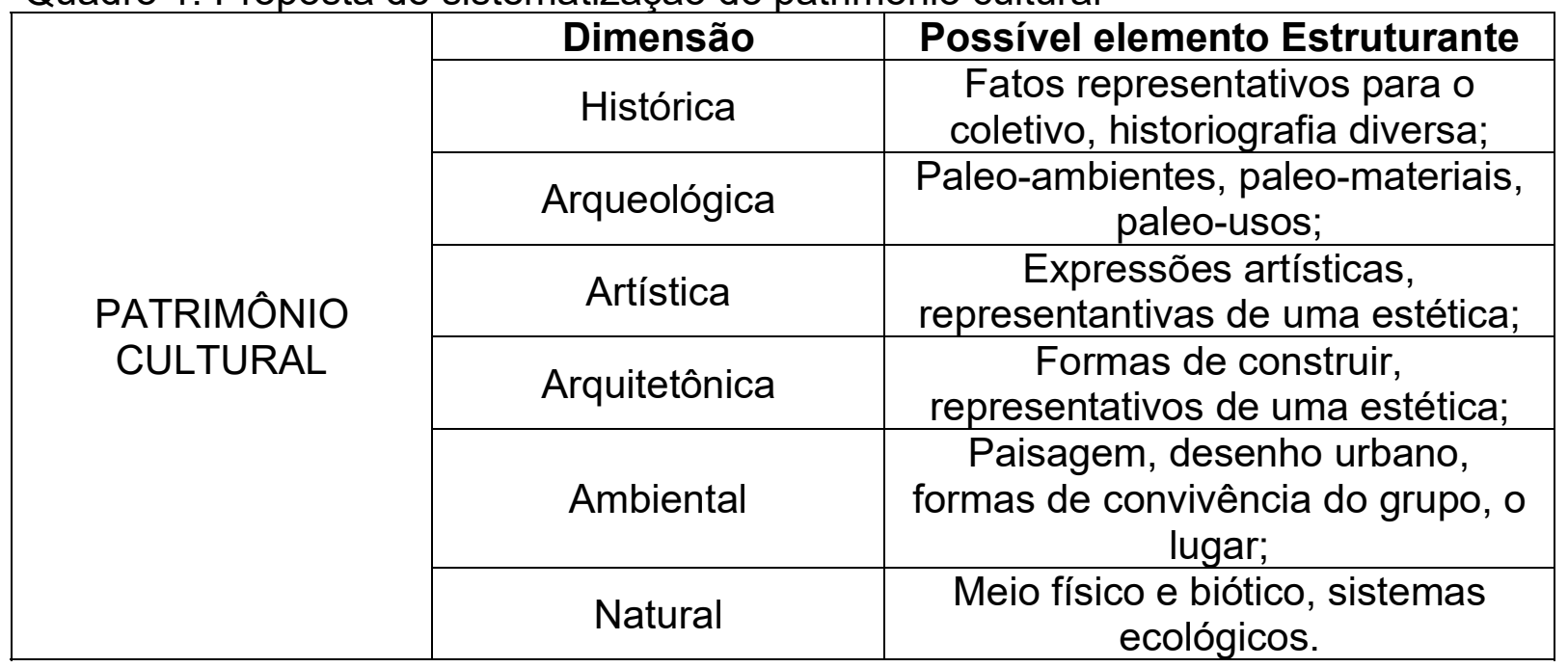

Elab.: Detoni, S. F. (2018)

A proposta apresentada não considera a inclusão do denominado patrimônio turístico, visto que tal derivação faz parte de uma dimensão econômica e não cultural. É importante destacar que qualquer dimensão do patrimônio cultural pode perpassar pela sua apropriação do setor turístico. Entretanto, o ato jurídico de reconhecimento da importância patrimonial não deve permear a finalidade de exploração turística. É claro que pode existir um potencial turístico a ser incluído nas práticas de divulgação, mas a patrimonialização por meio do reconhecimento cultural visa, exclusivamente, a sua identificação, reconhecimento, proteção e a aplicação de estratégias para a divulgação baseadas na educação patrimonial.

A prática de apropriação turística preconiza a exploração econômica que se desconecta do sentido prático do patrimônio cultural e pode ser nocivo a sua proteção. Tem-se o que Meneses (2012) denominou como cultura-cólica ou espasmos culturais, pois, de forma geral, no turismo, a cultura é algo à parte da vida e constitui-se num compartimento nobre e nobilitante, como descreveu o próprio autor:

São espaços, tempos e compartimentos desejáveis e prescritos, embora descontínuos e, em regra geral, excluídos do cotidiano e do universo do trabalho, duas referências que marcam contextos essenciais da existência humana. Constituem focos de condensação, que podem atingir picos de intensidade, mas depois se esvaziam: é a cultura-cólica. Ao espasmo segue-se o descongestionamento progressivo e a volta ao ponto de partida. É a cultura dos produtos culturais, dos produtores, dos consumidores, equipamentos, instituições, espaços, organismos, órgãos públicos, mercados. (MENESES, 2012, p. 28- 29).

Meneses (2012) argumentou que a relação com o patrimônio cultural pode ocorrer por meio de duas perspectivas: a aprofundada e a superficial. $\mathrm{O}$ turismo, em regra, abrange uma postura superficial. Tal relação está sistematizada por meio da propositiva do Quadro 2. 
Quadro 2. Interação cultural e turística sobre o patrimônio

\begin{tabular}{|c|c|}
\hline \multicolumn{2}{|c|}{ PERSPECTIVA DE INTERAÇÃO COM O PATRIMÔNIO } \\
\hline CULTURAL & TURISTICA \\
\hline PROFUNDIDADE & SUPERFICIALIDADE \\
INTENSIDADE & ATENUAÇÃO \\
INTERIORIDADE & EXTERIORIDADE \\
PERMANÊNCIA & DESCONTÍNUO \\
CONTÍNUO & PONTUAL \\
CONSCIENTE & DESTERRITORIALIZADA \\
APONTUAL & ANACRÔNICA \\
TERRITORIALIZADA & VOYEURISMO \\
REPRESENTATIVO & \\
\hline
\end{tabular}

Elab.: Detoni, S. F. (2018). Baseado em Meneses (2012)

Detoni (2016), ao analisar a distribuição geográfica, em diferentes escalas e o contexto da institucionalização dos bens culturais, verificou uma tendência a sua concentração espacial em determinadas porções dos territórios, acompanhada pela expansão e valorização mercadológica do patrimônio como objeto turístico.

A sua institucionalização no âmbito da United Nations Educational, Scientific and Cultural Organization (Unesco), por exemplo, por meio da inclusão de um patrimônio na Lista do Patrimônio Mundial, faz com que o objeto cultural passe a ter um status internacional e um apelo propagandístico para atrair turistas.

No âmbito do patrimônio cultural de objetos naturais, o denominado patrimônio natural, o turismo de massa predispõe uma infraestrutura adequada, o que pode ultrapassar a capacidade de suporte do ecossistema protegido e conduzir ao impacto ambiental negativo.

A institucionalização do patrimônio cultural no âmbito dos órgãos públicos brasileiros tem como instrumento fundamental o tombamento cultural. Essa palavra de origem lusitana prescreve a inclusão do bem de importância cultural num dos livros de tombo de um órgão público voltado para o reconhecimento dos objetos ou áreas de valor cultural.

Ao analisar o percurso prático de institucionalização do patrimônio natural no Brasil, especificamente, no Estado de São Paulo, uma das premissas encontradas diz respeito ao importante papel do órgão público de proteção cultural na defesa das estruturas paisagísticas do quadro natural. A proteção da Serra do Mar, em São Paulo, como uma Área Natural Tombada (ANT), insere-se num dos exemplos mais simbólicos dessa prática.

Verificou-se certa recorrência na utilização da sociedade civil em buscar o instrumento jurídico do tombamento para a proteção natural em função, principalmente, da forma desburocratizada de se protocolar um pedido para a abertura do processo de tombamento. Tal característica permite o acesso mais democrático às esferas institucionais, além da rapidez para a proteção, visto que, no momento que se abre o processo, o objeto de proteção não poderá ser modificado até a conclusão do rito processual. De outra forma, a proteção de uma área verde urbana, por exemplo, teria que passar por um processo burocrático que nem sempre encontra respaldo nos representantes legislativos, muitas vezes, orientados pela lógica do capital ou na condição de representantes diretos dos seus próprios 
interesses.

Dois momentos históricos devem ser destacados na condução da ideia de patrimônio cultural no Brasil: no plano internacional, a partir da criação dos chamados Estados-nacionais, embutiu-se a consciência de identidade cultural comum, materializada no território e no ideia de pertencimento a uma nação; já no plano interno, o marco inicial, encontra-se na independência política e no, posterior, processo de constituição de uma República Federativa. Assim, a Proclamação da República veio acompanhada de um novo ideário cultural, relacionado à superação do passado colonial, monárquico e do alinhamento aos espaços de modernidade do capitalismo mundial.

Pretendia-se moldar um povo para uma modernidade que fazia parte apenas do horizonte das elites políticas e intelectuais. A febre de cosmopolitismo que se instalou nas grandes cidades do país implicou a interferência no construir-se das identidades locais - especialmente as das camadas populares urbanas-, a negação dos hábitos tradicionais da sociedade brasileira, forjados em séculos de vivência do mundo rural e na transformação radical dos espaços urbanos. Nestes, a ampla adoção do eclético correspondeu ao gosto das elites dirigentes e evidenciou sua intenção de rompimento com o passado. (RODRIGUES, M., 2000, p. 17-18).

Dessa forma, a fase da construção de uma escola de pensamento que estruturaria as bases do que seria o patrimônio cultural no Brasil, a partir do início da República, caracteriza-se, sobretudo, pela valorização dos atributos arquitetônicos ecléticos das edificações.

No início do século $X X$, surgem as instituições e as discussões intelectuais que teorizavam sobre a postura cultural nacional e buscavam empreender os aspectos estruturadores de uma cultura brasileira. Sugere-se que o marco desse processo será consolidado no texto da Constituição Federal de 1937, ao incluir a proteção pelos entes governamentais dos monumentos históricos, artísticos e naturais, juntamente com as paisagens e locais dotados de significados naturais. No mesmo ano, ocorre a edição da primeira lei federal específica para a proteção do patrimônio, que incluiu os monumentos naturais como patrimônio nacional, ou seja, a incorporação da natureza no âmbito das práticas de preservação cultural.

Do ponto de vista jurídico, o Decreto-lei Federal n. 25 de 1937, editado no período totalitário, é o instrumento que organizou a proteção do patrimônio histórico e artístico nacional. Tal decreto também equiparou os bens de valores históricos e culturais aos monumentos naturais, sítios e paisagens cabíveis de conservação e proteção por sua feição notável, decorrente do seu atributo natural ou construção humana.

O instrumento jurídico que regulamentou a proteção e a defesa dos bens culturais baseou-se no anteprojeto, elaborado em 1936, pelo poeta e escritor Mário de Andrade. Entretanto, a preservação de áreas naturais não foi cogitada nesse escopo legal. Segundo Andrade (1984), a proteção das paisagens, mencionada no anteprojeto, baseava-se nas formações determinadas pela indústria humana, ou seja, enquanto suporte de atividades humanas de interesse cultural, sobretudo, na dimensão arqueológica e antropológica. Contudo, na redação do Decreto-lei n. 25, ampliou-se as possibilidades paisagísticas, no momento que se incluíram os monumentos naturais, bem como os sítios e paisagens que importe conservar e proteger por feição notável ou por ação humana. 
O tombamento passou a ser o principal instrumento de proteção ao patrimônio cultural, cuja anotação se efetua nos seguintes livros de tombo existentes no Instituto do Patrimônio Histórico e Artístico Nacional (Iphan): Arqueológico, Etnográfico e Paisagístico; Artes Aplicadas; Belas Artes; e Histórico. Por outro lado, a natureza será incorporada ao patrimônio cultural por meio de diferentes especificidades.

A proteção da natureza, no contexto de uma ação da política cultural, buscou na paisagem o atributo centralizador para a sua concretização. As experiências práticas foram aquém de considerá-la apenas como suporte ou ambiência de perspectivas históricas e arquitetônicas, da sua beleza notável e mesmo do seu valor como testemunho natural. Verificou-se o desenvolvimento de uma estrutura teórica e metodológica capaz incluí-la como parte de um movimento de apropriação social, no qual a sua defesa também envolvia a luta contra ação exploratória econômica. Contudo, tais experiências tiveram pouca representação no órgão federal de preservação do patrimônio cultural que incluiu a vertente natural por meio do conceito de paisagem cultural, o que culminaria com a edição da Portaria do Iphan n. 127 de 2009 que estabeleceu a chancela da paisagem cultural brasileira.

Definiu-se, no texto legal, que a paisagem cultural brasileira refere-se ao processo de interação do Homem com o meio natural, onde a ciência humana imprimiu as marcas ou atribuiu valores. Tal postura, mesmo que expresse o caráter sistêmico da paisagem, carrega certa dúvida quando a questão se relaciona à importância ecológica natural da paisagem. Todavia, a incorporação da natureza como um objeto cultural apresentou outras dimensões teóricas que consideraram os seus atributos intrínsecos.

\section{PATRIMÔNIO CULTURAL NO ESTADO DE SÃO PAULO}

A diversidade, a quantidade e os aspectos regionais sobrecarregaram, progressivamente, as atribuições do órgão federal, o que influiu no estabelecimento de instituições locais de defesa do patrimônio, sobretudo, a partir da década de 1960. Nesse contexto, em 1967 (lei publicada em 1968), mais uma vez durante o estabelecimento de Estado ditatorial, foi criado, no âmbito estadual, o Condephaat.

Para Rodrigues, C. (2001), num primeiro momento, o Condephaat é uma resposta à sobrecarga do Iphan, complementando as suas atividades. $O$ órgão paulista, no decorrer dos anos, passa a concentrar os pedidos de tombamento do estado. Todavia, é importante destacar que, em virtude da concepção teórica e ideológica adotada pelo Iphan, a abertura de processos que decorreram em tombamentos pelo órgão federal no estado, no período de 1938 a 1968, foi de apenas 52, visto que, no mesmo período, em Minas Gerais, essa quantidade foi de 178 processos. Com isso, fez necessária a regionalização da política cultural com intuito de valorizar determinadas especificidades.

$\mathrm{Na}$ perspectiva histórica, o processo de criação do órgão de patrimônio cultural paulista se inicia na década de 1930, dentro dos ideais educacionais do período. Em 1934, é criado o Departamento de Cultura da Capital por meio do projeto de Mário de Andrade e Paulo Duarte ${ }^{4}$. Entre as funções educacionais e de pesquisa, o Departamento tinha também como objetivo a defesa do patrimônio artístico e histórico do município.

Os esforços para a estruturação de uma instituição de patrimônio cultural na

\footnotetext{
${ }^{4}$ Paulo Alfeu Junqueira Duarte, professor de pré-história na Universidade de São Paulo
} 
Capital foram concomitantes à articulação de um órgão de preservação patrimonial para o estado. Porém, a centralização federal e as questões políticas no âmbito estadual estenderam esse processo até o final da década de 1960. Nesse contexto, deve-se destacar que a legislação de tombamento é autônoma e concorrente, ou seja, cada nível de gestão possui a sua legislação especifica. No Estado de São Paulo, a Lei Estadual n. 10.247 de 1968 atribui ao Condephaat, órgão vinculado à Secretaria de Estado da Cultura (SC) $)^{5}$, a competência para propor às autoridades competentes o tombamento, ou seja, o Condephaat não realiza 0 ato de tombamento, mas elabora o processo e pode opinar previamente sobre a matéria, visto que a homologação do tombamento é uma prerrogativa do secretário da cultura ${ }^{6}$.

De acordo com o art. 14 do Decreto Estadual n. 13.426 de 1979, o Conselho manteria cinco Livros de Tombo ${ }^{7}$. $\mathrm{O}$ tombamento de áreas naturais é registrado no Livro I, denominado Livro do Tombo Arqueológico, Etnográfico e Paisagístico. A lei estadual reforçou a ideia de que o conceito de patrimônio paisagístico relaciona-se aos monumentos naturais, por isso, numa interpretação pragmática, destacam-se os seus aspectos de raridade e da singularidade do bem tombado. No entanto, importantes práticas de preservação foram empreendidas no âmbito do Condephaat e o patrimônio natural passou a representar novas significações.

O pedido de tombamento pode partir da sociedade civil, dos conselheiros e técnicos do órgão ou dos diversos entes da administração pública, tais como membros do executivo ou do legislativo. Esse pedido inicial ${ }^{8}$ é apreciado por meio de uma pesquisa preliminar para a emissão de um parecer técnico que pode ser favorável ou não à abertura do processo de tombamento. Uma vez favorável, o processo é aberto para que ocorra uma pesquisa detalhada, fato que já institui a sua proteção legal. Posteriormente, encaminha-se à deliberação final dos conselheiros. A partir da sua aprovação, os proprietários são notificados individualmente ou por meio de uma publicação oficial que pode gerar a manifestação contestatória. É necessária que o órgão responda as manifestações, para que a resolução seja publicada. $O$ tombamento é homologado via resolução do secretário da cultura após a manifestação favorável do colegiado. Nesse sentido, o secretário da cultura possui poderes para rejeitar o pedido de tombamento nessa última instância.

A sensibilização deve ser composta, preferencialmente, por critérios e argumentos objetivos. Dessa forma, torna-se importante constituir um coeso embasamento teórico na defesa dos argumentos pró-tombamento, principalmente, quanto se relaciona a uma área natural ou uma paisagem de referência.

É importante ressaltar que o processo de reconhecimento de um patrimônio cultural perpassa pela consolidação do acesso aos direitos básicos e pode ser compreendido como a ampliação do conceito de cidadania: "Juntamente com o direito à memória, o direito ao patrimônio enseja que bens materiais investidos de função mnemônica sejam efetivamente protegidos. Afinal é reconhecimento do próprio grupo social e o situa no mundo. Paradoxalmente, é a própria percepção da mudança que remete ao sentido da memória e também ao de identidade." (RODRIGUES, C., 2001, p. 25).

O Condephaat passou a desempenhar o papel central na preservação e na

\footnotetext{
${ }^{5} \mathrm{Na}$ época Secretaria de Cultura, Esporte e Turismo.

${ }^{6}$ A Lei Estadual 50.941 de 2006 apresenta a última reorganização da Secretaria de Estado da Cultura.

${ }^{7}$ Há registros de bens tombados somente nos seguintes Livros: o Arqueológico, Etnográfico e Paisagístico, o das Artes e o Histórico.

${ }^{8}$ Denominado Guichê
} 
defesa do patrimônio cultural no estado de São Paulo. Por um lado, o dinamismo econômico do estado que cria as condições para a reprodução do capital e enseja modificações espaciais com base na forte especulação imobiliária, impôs ao órgão, no decorrer de sua história, às mais diversas pressões e questionamentos. Por outro lado, a perspectiva da utilização do patrimônio cultural como uma mercadoria turística, permitiu a sua apropriação econômica e o insere também numa lógica especulativa, conforme argumentou Rodrigues, M. (2000):

A criação do órgão de proteção ao patrimônio em São Paulo inscreveu-se nos contornos do culto cívico ao passado e da consagração pragmática desse mesmo passado, enquanto produto de consumo cultural valorizado com a expansão da indústria do turismo. Essas concepções opunham-se àquela, de matriz modernista, que orientara a formação do $\operatorname{Sphan}^{9}$ e dos profissionais que atuavam no "Patrimônio", segundo a qual o passado era referência para a constituição da nacionalidade $e$ fonte de conhecimento da História da Arquitetura. (RODRIGUES, M., 2000, p. 46).

O órgão estadual também foi concebido em torno de ideais ortodoxos que o vinculam a uma historiografia oficial. "A criação do Condephaat tornou-se possível quando frações conservadoras e tradicionalistas da burguesia paulista buscaram reafirmar a identidade bandeirante nos limites do quadro autoritário estabelecido em 1964." (RODRIGUES, M., 2000, p. 41).

Esse primeiro momento, relativo ao período colonial, foi sucedido pelo ideário da preservação envolvendo os ciclos econômicos do café e industrial. Para Rodrigues, M. (2000), reconhecer o valor do patrimônio cultual da indústria significou incorporar à produção cultural as fases mais recentes da história, preservar os espaços que continuavam vivos na memória da população urbana. Todavia, observou-se em todas as dimensões de proteção patrimonial, a inexistência da normatização de critérios. Na falta de uma política cultural prevaleciam as vontades individuais que encontraram um ambiente de interação e compartilhamento de pressupostos comuns.

O desenvolvimento discursivo sobre as práticas patrimoniais adquiriu destaque no momento em que determinadas intervenções urbanísticas passam a ser contestadas por um grupo social. Um caso emblemático refere-se à defesa da Escola Caetano de Campos, na região central da Capital do estado de São Paulo. A mobilização social em favor da preservação desse patrimônio foi tamanha que, a partir daí, a prática do tombamento tornou-se aliada do planejamento ambiental. Rodrigues, C. (2001) afirma que apesar do caráter afetivo do caso do Caetano de Campos, o seu tombamento pautou-se, principalmente, em elementos relacionados à sua importância histórica relativa ao ensino público nacional. "Em primeiro lugar, tal campanha trouxe à tona uma crítica veemente à égide essencialmente tecnocrática da administração pública. As inúmeras intervenções urbanísticas que a cidade vinha sofrendo, vinham causando a destruição de referenciais construtivos e paisagísticos de grande valor afetivo para a população, como era o caso do próprio Instituto." (RODRIGUES, C., 2001, p. 84).

Juntamente com o aumento das solicitações de tombamento, abriu-se a oportunidade para se efetuar a preservação de áreas naturais no contexto dos instrumentos legais existentes na proteção institucional de cunho cultural. $O$

\footnotetext{
${ }^{9}$ Serviço do Patrimônio Histórico e Artístico Nacional.
} 
Condephaat passou a ser pioneiro na utilização do tombamento de áreas naturais e afirmou o critério ambiental como elemento construtivo do bem cultural (RODRIGUES, C. N., 2001).

Sugere-se que o ápice da valorização do patrimônio natural no Condephaat ocorreu com a criação da Equipe de Áreas Naturais dentro do Serviço Técnico e Conservação e Restauro (STCR). Todavia, a equipe foi desativada na gestão do governador Mario Covas (década de 1990), o que indicava o desprestígio posterior dessa importante forma para a defesa e proteção de áreas naturais.

Até o ano de 2014, foram inscritos nos livros de tombo da instituição 514 patrimônios. Apesar de experiências inovadoras com relação à incorporação de novas práticas de preservação cultural que incluíram a dimensão natural e ambiental, mais de $91 \%$ dos tombamentos foram inscritos no livro do tombo histórico. O Livro Arqueológico, Etnológico e Paisagístico contava com 7\% dos registros, o que correspondeu a 36 inscrições. (Gráfico 1). Outro aspecto importante se relaciona à concentração espacial dos tombamentos, por meio do Mapa expresso pela Figura 1, é possível inferir que uma parte significativa dos tombamentos do Estado de São Paulo se inseria numa perspectiva histórica arquitetônica, com destaque para o ciclo econômico cafeeiro ocorrido no Estado.

A Capital paulista concentrava o maior número de bens tombados, o que correspondia por volta de $28 \%$ do total. Os tombamentos efetuados pelo Condephaat abarcavam pouco mais de $30 \%$ dos municípios do Estado, o que corresponde a somente 199 municípios $^{10}$, num universo de 645 . Ao analisar os municípios que possuíam bens tombados pelo órgão, por volta de $79 \%$ participavam em menos de $0,5 \%$ do universo percentual dos tombamentos. A Figura 1 demonstra que os municípios que possuíam maiores inscrições nos livros de tombo da instituição seguem, preferencialmente, a orientação da expansão da lavoura de café, a partir do século XIX, o que abrange uma faixa mais concisa que vai do Vale do Paraíba Paulista, Região de Campinas e Ribeirão Preto. Nesse sentido, os incipientes registros dos patrimônios culturais no Oeste Paulista sugerem a necessidade do órgão em adotar novas dimensões e a ampliação do reconhecimento patrimonial com base em outras dimensões temáticas.

Gráfico 1. Distribuição das inscrições dos tombamentos por Livros ${ }^{11}$

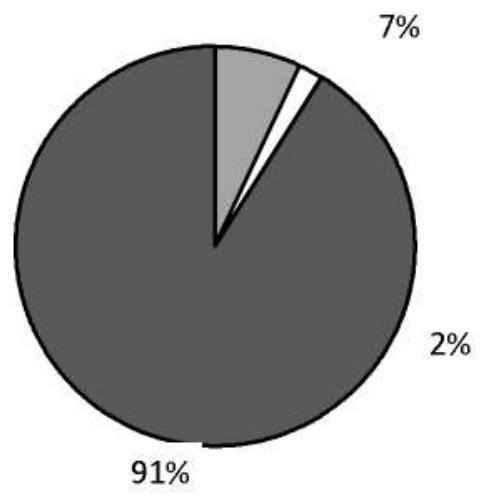

Arqueológico,

Etnográfico e

Paisagístico

$\square$ Artes

Histórico

Fonte dos dados: Lista de Bens Tombados Condephaat

\footnotetext{
${ }^{10}$ Algumas áreas naturais tombadas, como a da Serra do Mar e de Paranapiacaba abrangem 44 municípios. Os bens móveis também possuem características peculiares: as obras do pintor Benedito Calixto de Jesus se encontram distribuídas por 8 municípios; nas obras do pintor José Ferraz de Almeida Júnior, não há referências de localização.

${ }^{11}$ Total individual, sem contar a abrangência municipal.
} 
(Disponível em www.condephaat.sp.gov.br). Org. por Detoni, S. F. (2018)

Figura 1 Mapa da Distribuição relativa por municípios dos tombamentos culturais do Condephaat até o ano de 2014

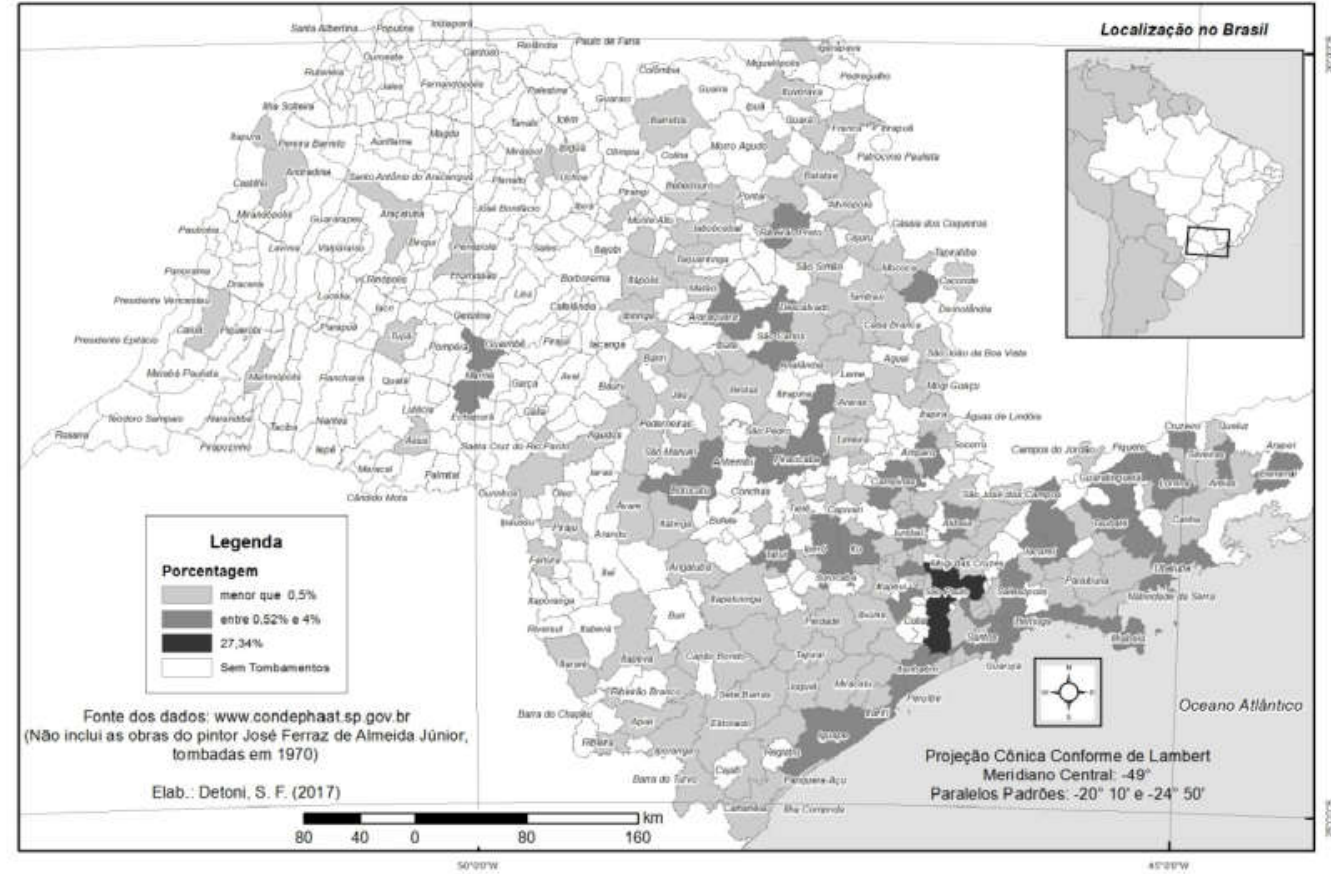

\section{TOMBAMENTO NATURAL NO ESTADO DE SÃO PAULO}

Scifoni (2008) destacou os aspectos relativos à dimensão quantitativa e qualitativa do tombamento de áreas naturais no estado de São Paulo. Além da expressiva quantidade de bens tombados, a definição de critérios, o desenvolvimento conceitual e metodológico com importante contribuição da Geografia são os fatores que contribuíram e fez da experiência paulista um exemplo positivo no tratamento da proteção da natureza na esfera da cultura.

É importante frisar que a proteção da natureza surge, num primeiro momento, como um fato cultural. O discurso sobre a necessidade efetiva da proteção dos ecossistemas naturais encontrou um conjunto sistematizado e institucionalizado nas políticas de preservação do patrimônio cultural e que serviu de referência para a montagem do escopo lógico da proteção natural stricto sensu, sobretudo, ao partir dos preceitos conceituais do patrimônio.

A inclusão quadro natural no interior de um órgão dinamizador de políticas de defesa e proteção cultural se apresentou de forma conflituosa. Por isso, havia a necessidade do desenvolvimento de um aparato conceitual capaz de sustentar as posições contrárias vindas de diferentes vertentes acadêmicas e, sobretudo, econômicas, visto que essas últimas percebiam o espaço geográfico como uma oportunidade a reprodução do capital. Tais conflitos foram demarcados por meio dos posicionamentos ideológicos e expostos pelas possibilidades de apropriação espacial coletiva, o que caracterizou uma lógica, muitas vezes, permeada pelo embate entre o público e o privado. 
Inicialmente, interpreta-se que a dificuldade de se consolidar o discurso patrimonial com o foco nos objetos da natureza reside, possivelmente, na tendência científica de separação das atribuições temáticas decorrente de uma racionalidade iluminista, reforçado nas escolas positivistas, e que consolidou a premissa da separação rígida entre as ciências. Ainda assim, mesmo que patrimônio natural seja considerado um instrumento de proteção na interface cultural-natural, os focos de resistências se amparavam num conjunto argumentativo que buscava a desregulamentação ações com apoio da estrutura jurídica.

Por outro lado, o conjunto de argumentos teóricos e a construção ideológica sobre o acautelamento do ecossistema natural no contexto de uma ação de proteção cultural subsidiou a criação das ANTs no estado de São Paulo. A partir da construção teórica e ideológica, tornou-se essencial o desenvolvimento dos aspectos conceituais e metodológicos dessa empreitada no domínio institucional do Condephaat.

A proteção da natureza por meio das políticas públicas de cunho cultural partiu da inclusão da análise ambiental no escopo do planejamento urbano e regional. Tais políticas que seguiam uma orientação tecnicista da administração pública incluíam a necessidade de preservação do meio ambiente que foi respaldado, no caso do Condephaat, por um Programa de Preservação e Revitalização do Patrimônio Ambiental Urbano.

Ao analisar o trabalho de Rodrigues, M. (2000), é possível afirmar que uma das primeiras menções oficiais do Condephaat com o intuito de estruturar alguma diretriz para o patrimônio natural adveio da apresentação do documento "Proposta e Roteiro Para a Atuação do Novo Conselho Deliberativo do Condephaat", elaborado por Ulpiano Bezerra de Meneses, no início da gestão de Nestor Goulart Reis Filho, em 1976, no qual se propôs a proteção e valorização do patrimônio natural.

A institucionalização dos bens patrimoniais culturais, em função de suas características naturais, demonstrou-se como um importante instrumento para a defesa e preservação de ecossistemas e de espaços para a garantia da qualidade ambiental urbana. Entretanto, verificou-se que a legislação de tombamento, apesar de genérica em todas as tipologias, é marcada por uma estrutura voltada para a proteção do patrimônio histórico, artístico e arquitetônico, o chamado "pedra e cal", fato que influenciará a ação do Condephaat nos primeiros anos de atuação. Para Rodrigues, M. (2000):

O excessivo cuidado com a História da Arquitetura chegava a ser um empecilho à adoção de condutas determinadas por outras motivações. O apego aos critérios tradicionais de eleição do patrimônio edificado encontrava correspondência no campo jurídico, pois oferecia um instrumento legal para o exercício da proteção do Estado, o tombamento. O tradicionalismo da área preservacionista faria crescer a incompatibilidade entre as ações de proteção e a dinâmica da própria sociedade, em especial nas grandes cidades onde a especulação imobiliária via no tombamento uma restrição de suas possibilidades de expansão. (RODRIGUES, M., 2000, p. 65).

Com isso, num primeiro momento, a paisagem era utilizada como afirmação do valor histórico dos bens tomados. No decorrer do desenvolvimento prático, apropriou-se do termo paisagem presente nas cartas legais para criar e sistematizar a preservação da natureza, conforme demonstrou a análise efetuada por Detoni (2016). 
À medida que surgiram as ações práticas, verificou-se que no Condephaat se empreendeu uma discussão intelectual sobre o que deveria ser objeto de políticas culturais, no caso específico, de tombamento. Nesses termos, a vertente ortodoxa questionou a validade da natureza como patrimônio cultural que, gradativamente, foi incorporada como objeto de proteção, consubstanciado por meio de uma base teórica e conceitual concisa.

O patrimônio natural, segundo a interpretação de Rodrigues, M. (2000), é a "memória" da natureza, no sentido de testemunhar os processos naturais, mas também pode ser uma referência histórica inserida na memória social. Nesse último caso, o quadro natural, na amplitude de patrimônio cultural, deve ser relevante ao grupo social.

As características dinâmicas das paisagens faz com que o tombamento se insira num ato político de interferência na produção do espaço geográfico, para salvaguardar, tanto a memória da natureza, relacionada à história natural, como as formas de apropriação cultural do espaço. Acima de tudo, a questão do patrimônio natural é um tema geográfico. Verifica-se, assim, que o tombamento natural, ao incidir em extensas áreas, submete-as a um regime jurídico que atrela o uso do solo às regras de preservação, interferindo, portanto, na atuação dos agentes públicos e privados na produção do espaço geográfico. Ao impor, em casos específicos, normas mais rígidas do que a legislação urbanística comum, ele seleciona usos e restringe determinadas formas de ocupação do solo, possibilitando a criação de uma nova dinâmica espacial. Por outro lado, o tombamento também valoriza determinadas áreas, ao reconhecê-las como patrimônio do Estado, fomentado novas perspectivas de exploração econômica (SCIFONI, 2008, p. 11).

Em determinados aspectos, o tombamento foi um importante instrumento de preservação ao interferir não somente na dinâmica de exploração econômica da Serra do Mar e conter procedimentos advindos da especulação imobiliária, marcados pelo acelerado processo de urbanização, sobretudo, na utilização de terra para a exploração do turismo, mas também ao fomentar o debate sobre a relevância cultural daquele bem natural.

Pode-se afirmar que a influência da Geografia nas políticas culturais, com vista à proteção do patrimônio natural e também à construção conceitual do que deveria ser considerado como patrimônio natural, adquiriu um importante instrumento norteador a partir elaboração do texto do professor Aziz Nacib Ab'Sáber, em 1977, na qualidade de representante do Departamento de Geografia da Faculdade de Filosofia Letras e Ciências Humanas da Universidade de São Paulo, junto ao Condephaat, denominado Diretrizes para uma Política de Preservação de Reservas Naturais do Estado de São Paulo.

Para Ab'Sáber (1977), naquele momento, as diretrizes de preservação de reservas naturais no estado de São Paulo se encontravam no estágio de estudos básicos com considerações genéricas e um grande número de órgãos, cujo objetivo era o de administrar fatos isolados da natureza e do patrimônio ambiental sem atentar-se ao efetivo gerenciamento do quadro global de potencialidades herdadas dos fatores naturais. Ab'Sáber assistia uma forte degradação ambiental dos recursos naturais no estado, face à crescente urbanização e ao desenvolvimento industrial paulista, conforme o próprio pesquisador descreveu: "Evidentemente, não se pode elaborar um corpo de diretrizes para a preservação de reservas naturais sem se levar em conta as dimensões do território, sua compartimentação topográfica e ecológica, e a densidade de ocupação e uso de seus solos. Sobretudo não se pode deixar de considerar o nível atual de urbanização e industrialização." 
(AB'SÁBER, 1977, p. 1).

O território paulista apresentava e apresenta uma forte valorização da terra, sobretudo, em virtude de sua infraestrutura, o que, na análise de Ab'Sáber (1977), diminui as possibilidades de se reservar áreas para uso comunitário, a serviço da sociedade como um todo. Alertava-se que qualquer política inconsistente de retenção de áreas para uso social e cultural sofreria com a pressão da especulação imobiliária desenfreada e incontrolável. O autor traçava o quadro de possibilidades para o desenvolvimento e para o estabelecimento de uma razoável política de preservação de espaços naturais pautada nos seguintes pressupostos: filtragem da biosfera, reservas biológicas, áreas de lazer e pontos turísticos. Assim, as possibilidades de proteção do patrimônio natural deveriam incluir o contexto cultural e não somente a situação ecológica natural do bem tombado, mas o desenvolvimento prático da proteção do patrimônio ambiental urbano. Para Scifoni (2008):

A noção de patrimônio ambiental urbano, porquanto questionou os critérios tradicionais de valor, contribuiu para reforçar a ideia de que o patrimônio natural não se referia somente a testemunhos de uma beleza natural excepcional. Tratava-se de um novo critério, o de reconhecer valor em expressões de uma natureza transformada e apropriada socialmente, uma natureza "comum", dos parques e áreas verdes urbanas, por exemplo, com um amplo uso e, portanto, um amplo significado social. (SCIFONI, 2008, p. 110).

Ab'Sáber (1977), neste trabalho, também atentou sobre a inoperância das leis sobre o uso, controle e zoneamento do solo urbano, periurbano e rural, tese confirmada pelo trabalho de Rodrigues, C. (2001), no qual se verificou a relação entre as reivindicações por tombamentos no município de São Paulo e o não cumprimento das leis de uso e ocupação do solo, fruto da pressão sobre o legislativo municipal para a alteração dos zoneamentos do município, quando havia um interesse mercadológico. O geógrafo propôs, assim, um zoneamento racional das áreas periféricas com o intuito de garantir espaços verdes, encaminhada por uma política seletiva de identificação de áreas para proteger os quadros significativos da natureza paisagística e ecológica no território paulista, em que as diretrizes seriam estruturadas no contexto dos conhecimentos básicos das ciências naturais e do planejamento regional integrado.

Em resumo, as diretrizes propostas por Ab'Sáber (1977) procuraram compatibilizar os aspectos sociais no âmbito do planejamento ambiental, em que se definiam as áreas críticas para a proteção ambiental, principalmente, na Região Metropolitana de São Paulo (RMSP) em função da importância natural e paisagística na sua condição de patrimônio cultural.

O processo de tombamento da Serra do Mar, aberto em 1979, com parecer do Professor do Professor José Pereira de Queiroz Neto, representante do Departamento de Geografia da USP, permitiu a discussão sobre a sistematização dos critérios para a inclusão dessa política de proteção do meio ambiente na esfera cultural, visto que ainda havia em andamento outros processos de tombamento com essa temática, entre os quais, o do Parque Estadual do Jaraguá, a Reserva Florestal do Morro Grande e o da Serra do Japi. Tais demandas resultaram na criação de um Grupo de Trabalho (GT), no mesmo ano, para elaboração do documento intitulado "Subsídios para um Plano Sistematizador das Paisagens Naturais do Estado de São Paulo", descrito e regulamentado por meio da Ordem de Serviço n. 01 de 1982 
(CONDEPHAAT, 1982). Verifica-se que as diretrizes básicas contidas nesse documento possuem fundamentação na proposta encaminha por Ab'Sáber (1977). Porém, o pesquisador não participou do GT que foi coordenado pela professora do Departamento de Geografia da USP, Lea Goldestein.

É importante ressaltar que a ação do grupo temático formado no órgão e o marco regulatório dado por esse documento, juntamente com o respaldo da sociedade civil organizada de diferentes formas, permitiram a proteção imediata de importantes áreas naturais no Estado de São Paulo. Posteriormente, o Grupo de Trabalho deu origem a Equipe Técnica de Áreas Naturais, que foi a grande fomentadora da ampliação do tombamento de áreas naturais.

O estabelecimento de diretrizes específicas fundamentou as práticas referentes aos tombamentos naturais e demonstrou a sua importância, em vista da ampliação do número de pedidos. Segundo Scifoni (2006), na década de 1980 ocorreram 59 pedidos de tombamentos, relacionados à dimensão natural do patrimônio, período que também ocorreu o menor tempo de tramitação entre o pedido e a homologação do tombamento. A mesma pesquisadora definiu o período, entre 1981 a $1991^{12}$, como de "Momentos Progressistas". Período que Rodrigues, C. (2001), em seu trabalho, já havia classificado como "Tempos de Abertura".

Respaldado juridicamente e com apoio teórico metodológico e conceitual da ciência geográfica, o Condephaat foi precursor na inclusão de novas perspectivas para a seleção de objetos culturais a se proteger. Nesse ambiente institucional, desenvolveu-se um conjunto de diretrizes capaz de sustentar e validar as práticas que foram executadas. Diante das diversas tipologias que envolveram a proteção paisagística e ecossistêmica, sistematizaram-se os conceitos de forma objetiva e aplicável, não somente à área direta de tombamento, mas também ao seu entorno imediato.

$\mathrm{Na}$ legislação vigente, a paisagem e o patrimônio interagem com os conceitos de natureza, natural e ambiental. Dessa forma, no contexto do tombamento, uma paisagem pode ser um patrimônio natural ou ambiental.

Fatores políticos, tanto de ordem externa como interna, contribuíram para a construção da postura progressista do órgão, sobretudo, no que diz respeito ao processo de redemocratização do país e da ampla mobilização social em prol desse instrumento de proteção.

Sejam as entidades ambientalistas ou a sociedade civil organizada, por exemplo, em associações de bairros, o fato é que o tombamento natural permeou a defesa do meio ambiente nas mais diversas amplitudes e tiveram a sua fundamentação inicial descritas na proposta elaborada pelo geógrafo e professor Aziz Nacib Ab'Sáber.

Grande parte dos pedidos de proteção motivara-se sob alguma ameaça que sobrepunha o interesse privado, em detrimento do espaço público e função da expropriação dos direitos coletivos. Para Scifoni (2006), o tombamento foi visto como uma forma de garantir o uso e apropriação social do espaço da cidade que era ameaçado por uma lógica de produção do urbano com prioridade ao valor de troca em detrimento ao valor de uso. Nessa lógica de valorização do capital, a área verde era interpretada apenas como um espaço ocioso disponível para ser ocupado e empreendido.

\footnotetext{
${ }^{12}$ Gestões na presidência do órgão: Aziz Nacib Ab'Sáber, Antonio Arantes, Modesto Carvalhosa, Paulo Bastos, Augusto Umberto Vairo Titarelli e Edgard de Assis Carvalho.
} 


\section{CONSIDERAÇÕES FINAIS}

Apesar do caráter coletivo, as expressões culturais são apropriadas pelas estruturas de poder e podem servir ao jogo ideológico da dominação. Nesse sentido, assistiu-se a elaboração dos principais instrumentos jurídicos que versam sobre o patrimônio cultural, tanto na esfera federal como na estadual, durante regimes ditatoriais. Por outro lado, procurou-se no contexto institucional expressar o dinamismo cultural por meio da inclusão de novos dimensionamentos.

A proteção da natureza é, fundamentalmente, um fato cultural. Para a institucionalização do patrimônio natural no Condephaat tornou-se necessário ordenar um conjunto de argumentos que referendassem as ações empreendidas no órgão.

Um dos propósitos que envolvem a proteção dos ecossistemas naturais está o de garantir o equilíbrio ambiental de determinada porção territorial. Assim, a proteção da integridade espacial enseja o caráter simbólico do quadro natural, o que coloca a natureza na condição de patrimônio cultural.

Diante do exposto, a natureza, na amplitude de seus aspectos simbólicos, caracteriza-se como uma das dimensões de patrimônio cultural. Por isso, devem-se incluir os seus elementos no contexto prático das políticas públicas de proteção cultural, ou seja, o tombamento natural.

Ressalta-se que na existência de um componente simbólico e do seu reconhecimento cultural coletivo - o que pressupõe a sua valorização -, estando ou não condicionado ao risco de suplantação, pode predispor da proteção na esfera da cultura, ou seja, o reconhecimento institucional.

Dessa forma, uma unidade de conservação da natureza, institucionalizada no âmbito dos órgãos de meio ambiente, pode ser um objeto de política cultural no momento em que se deseje reforçar o seu caráter simbólico para os membros do grupo social envolvido.

A experiência do Condephaat no tombamento de áreas naturais permitiu consolidar a natureza como um fato cultural. Isso se deve, sobretudo, à construção de uma linha teórica, metodológica e conceitual, ou seja, um corpus argumentativo que não somente orientou a condução dos tombamentos naturais, mas produziu um marco regulatório para a segurança jurídica das ações de tombamento natural.

\section{REFERÊNCIAS}

AB'SÁBER, A. N. Diretrizes para uma Política de Preservação de Reservas Naturais do Estado de São Paulo. Boletim de Geografia e Planejamento, São Paulo: Instituto de Geografia da USP, n. 30, p. 7-19, 1977.

ANDRADE, A. L. D. de. O Tombamento na Preservação de Áreas Naturais. Revista do Patrimônio Histórico e Artístico Nacional, Brasilia, 19, p. 41-44, 1984.

CONSELHO DE DEFESA DO PATRIMONIO HISTÓRICO, ARTÍSTICO, ARQUEOLÓGICO E TURÍSTICO DO ESTADO DE SÃO PAULO (CONDEPHAAT). Subsídios para um Plano Sistematizador das Paisagens Naturais do Estado de São Paulo. São Paulo: Condephaat, 1982. (Ordem de Serviço n. 01 de 1982). DETONI, S. F. Natureza e patrimônio cultural: a geomorfologia como referencial metodológico no tombamento de áreas naturais. Tese (Doutorado). Programa de Pós-Graduação em Geografia Física, Faculdade de Filosofia, Letras e Ciências Humanas da Universidade de São Paulo, São Paulo, 2016, 235 p. 
DURHAM, E. R. Cultura, Patrimônio e Preservação. Texto II. p. 23-59. In: Produzindo o Passado: Estratégias de proteção do patrimônio cultural, ARANTES, A. A. (org.). São Paulo: Brasiliense, 1984, 225 p.

MAGNANI, J. G. C. Pensar grande o patrimônio cultural. Lua Nova: Revista de Cultura e Política, São Paulo, v. 3, n. 2, dez. 1986.

MENESES, U. T. B de. O Patrimônio Cultural Entre o Público e o Privado. In: 0 Direito à Memória: Patrimônio Histórico e Cidadania. São Paulo (cidade). Secretaria Municipal de Cultura. Departamento do Patrimônio Histórico (DPH). São Paulo: DPH, 1992, p. 189-194.

Os "Usos Culturais" da Cultura: Contribuição para uma abordagem crítica das práticas e políticas culturais. In: Turismo: Espaço, Paisagem e Cultura. YÁZIGI, E.; CARLOS, A. F. A.; CRUZ, R. C. A. da. (orgs.) Editora Hucitec: São Paulo, 1996. p. 88-99.

. O Campo do Patrimônio Mundial: Uma Revisão de Premissas. p. 29-39. In: Instituto Nacional do Patrimônio Cultural (IPHAN). I Fórum Nacional de Patrimônio Cultural: Sistema Nacional de Patrimônio Cultural: desafios, estratégias e experiências para uma nova gestão, Ouro Preto/MG, 2009. Brasília, DF: Iphan, 2012, $404 \mathrm{p}$.

RODRIGUES, C. N. Território do Patrimônio: Tombamento e Participação Social na Cidade de São Paulo. Dissertação (Mestrado). Programa de Pósgraduação em Geografia Humana, Faculdade de Filosofia, Letras e Ciências Humanas da Universidade de São Paulo, São Paulo, 2001.

RODRIGUES, M. Imagens do passado: a instiutição do patrimônio em São Paulo (1969-1987). São Paulo: Editora UNESP: Imprensa Oficial do Estado: Condephaat: FAPESP, 2000, $181 \mathrm{p}$.

RÚSSIO, W. Cultura, Patrimônio e Preservação. Texto III. p. 59-79. In: Produzindo - Passado: Estratégias de proteção do patrimônio cultural. ARANTES, A. A. (org.). São Paulo: Brasiliense, 1984, 225 p.

SCIFONI, S. A Construção do Patrimônio Natural. Tese (Doutorado). Programa de Pós-Graduação em Geografia Humana, Faculdade de Filosofia, Letras e Ciências Humanas da Universidade de São Paulo, São Paulo, 2006, 293 p.

$199 \mathrm{p}$.

A construção do Patrimônio Natural (Livro). São Paulo: FFLCH, 2008, 